\title{
MODAFINIL TRIAL IN ATTENTION DEFICIT HYPERACTIVITY DISORDER
}

A film-coated tablet formulation of modafinil (Provigil ${ }^{\mathrm{R}}$ ) was used to treat a total of 246 patients, ages 6 to 17 years, with attention deficit hyperactivity disorder (ADHD) at the Massachusetts General Hospital, Boston, MA, and other centers. Intention-to-treat analysis (ITT) showed that compared with placebo $(n=82)$, treatment with modafinil $(170-425$ $\mathrm{mg} /$ once daily) in a 9-week, double-blind study, significantly improved core symptoms of ADHD, based on school and home rating scales. The most common adverse events were insomnia (29\%), headache $(20 \%)$, and decreased appetite $(16 \%) ; 3 \%$ of patients discontinued treatment because of adverse effects. These included erythyema multiforme, StevensJohnson syndrome, somnolence, dystonia, and tachycardia. (Biederman J, Swanson JM, Wigal SB et al. Efficacy and safety of modafinil film-coated tablets in children and aciolescents with attention-deficit/hyperactivity disorder: results of a randomized, doubleblind, placebo-controlled, flexible-dose study. Pediatrics December 2005;116:e777-e784). (Respond: Joseph Biederman MD, Pediatric Psychopharmacology Research Unit, Massachusetts General Hospital, Yawkey Center for Outpatient Care, Yaw-6A-6900, 32 Fruit St, Boston, MA 02114).

COMMENT. Modafinil is approved by the FDA as a Schedule C-IV medication for the promotion of wakefulness and treatment of narcolepsy in patients older than 16 years. It may result in an increase in extracellular dopamine, norepinephrine, and serotonin, binding primarily to neurons of the anterior hypothalamus (Scammell TE et al. $\mathbf{J}$ Neurosci 2000;20:8620-8). As another new agent in the treatment of ADHD, if approved for use in children, modafanil may prove of value as an alternative choice, when methylphenidate or amphetamine preparations have proven ineffective or not tolerated. Although the majority of adverse side-effects of modafinil appear to be mild or moderate (Rugino TA et al. Pediatr Neurol 2003;29:136-142; idem. J Am Acad Child Adolesc Psychiatry 2001;40:230-235), the occurrence of serious, life-threatening, skin reactions in 2 patients in the present study is troublesome.

Methylphenidate transdermal system (MTS) in ADHD has been studied in 36 children aged 7-12 years, using doses of $0.45,0.9$ and $1.8 \mathrm{mg} /$ hour, applied at 6 am or $7 \mathrm{am}$, and worn for at least 12 hours daily. At all doses studied, effects on behavior, classroom functioning, and parent ratings were significantly different from placebo. Effects of higher doses were not different from moderate dose effects. Effects lasted through 12 hours and in to evening until bedtime. Skin erythema was present after patch removal in $40 \%$ to $50 \%$, most dissipating by morning. Most patches adhered well through physical activity, even swimming. MTS may be useful as an alternative for children having difficulty in swallowing pills. (Pelham WE Jr et al. J Am Acad Child Adolesc Psychiatry 2005;44:522-529).

In April 2003, the USA FDA failed to approve the pending new drug application for MTS and requested additional clinical information. Noven and Shire Pharmaceuticals have a new clinical development plan to test efficacy, safety and tolerability of MTS, using shorter wear times (Mays DA, Findling R. J Am Acad Child Adolesc Psychiatry Dec 2005;44:1223). 